\title{
Suppressed hepcidin expression correlates with hypotransferrinemia in copper-deficient rat pups but not dams
}

\author{
Margaret Broderius $\cdot$ Elise Mostad $\cdot$ \\ Joseph R. Prohaska
}

Received: 9 January 2012 / Accepted: 10 March 2012/Published online: 29 March 2012

(C) Springer-Verlag 2012

\begin{abstract}
Copper deficiency leads to anemia but the mechanism is unknown. Copper deficiency also leads to hypoferremia, which may limit erythropoiesis. The hypoferremia may be due to limited function of multicopper oxidases (MCO) hephaestin in enterocytes or GPIceruloplasmin in macrophages of liver and spleen whose function as a ferroxidase is thought essential for iron transfer out of cells. Iron release may also be limited by ferroportin (Fpn), the iron efflux transporter. Fpn may be lower following copper deficiency because of impaired ferroxidase activity of MCO. Fpn is also dependent on the liver hormone hepcidin as Fpn is degraded when hepcidin binds to Fpn. Anemia and hypoferremia both down regulate hepcidin by separate mechanisms. Current studies confirmed and extended earlier studies with copper-deficient $(\mathrm{CuD})$ rats that suggested low hepicidin resulted in augmented Fpn. However, current studies in CuD dams failed to confirm a correlation that hepcidin expression was associated with low transferrin receptor 2 (TfR2) levels and also challenged the dogma that holotransferrin can explain the correlation with hepcidin. CuD dams exhibited hypoferremia, low liver TfR2, anemia in some rats, yet no depression in Hamp expression, the hepcidin gene. Normal levels of GDF-15, the putative erythroid cytokine that suppresses hepcidin, were detected in plasma of $\mathrm{CuD}$ and iron-deficient $(\mathrm{FeD})$ dams. Importantly, FeD dams did display greatly lower Hamp expression. Normal hepcidin in these $\mathrm{CuD}$ dams is
\end{abstract}

M. Broderius · E. Mostad · J. R. Prohaska $(\bowtie)$

Department of Biomedical Sciences, University of Minnesota

Medical School Duluth, 1035 University Drive,

Duluth, MN 55812, USA

e-mail: jprohask@d.umn.edu puzzling since these rats may need extra iron to meet needs of lactation and the impaired iron transfer noted previously.

Keywords Copper deficiency · Rats - Transferrin iron · Hepcidin · Anemia

\section{Introduction}

Limitation in the availability of the essential trace metal copper leads to a series of pathological consequences because copper is a required cofactor for about a dozen enzymes (Prohaska 2012). One such consequence is anemia reflected in a severe drop in erythrocyte cell number and lower hemoglobin content per cell. Copper supplementation can reverse this anemia as first documented in 1862 (Fox 2003). The precise mechanism for the anemia of copper deficiency is not known but is more complicated than the original ferroxidase hypothesis (Osaki et al. 1966). Copper-deficient $(\mathrm{CuD})$ rats and other species exhibit hypoferremia with anemia (Cartwright et al. 1956). Since ceruloplasmin (ferroxidase) null mice $(C p-/-)$ also exhibit hypoferremia, it seems logical to conclude that lack of copper can limit $\mathrm{Cp}$ function or other multicopper oxidases (MCO) function that impact iron efflux (Prohaska 2011).

However, iron efflux also depends on ferroportin (Fpn), the only known and essential iron efflux translocator (Donovan et al. 2005). It is believed that Fpn works in concert with tissue-specific MCO enzymes to convert ferrous to ferric iron to load transferrin (Tf), the plasma iron transport protein (Collins et al. 2010). Plasma membrane abundance of Fpn has been shown to depend on the ferroxidase activity of Cp (De Domenico et al. 2007). Thus, 
hypoferremia of $\mathrm{CuD}$ rats might be caused by lower $\mathrm{MCO}$ function or lower Fpn abundance.

Some believe that the abundance of Fpn is determined largely by hepcidin (Hepc), a liver hormone that binds Fpn and results in internalization and degradation (Nemeth et al. 2004). When Hepc is produced, iron absorption from the intestine and iron mobilization from macrophage stores are decreased by the destruction of Fpn. Hepc expression is regulated by a complex set of factors that include holotransferrin, IL-6, bone morphogenic protein 6 (BMP6), and putative factors that are released from bone marrow in response to anemia (Knutson 2010).

Recent studies in male $\mathrm{CuD}$ rat pups and postweanling male rats reported a profound reduction in Hamp expression (gene coding for hepcidin) (Jenkitkasemwong et al. 2010). These CuD rats had lower hemoglobin and plasma iron levels than copper-adequate $(\mathrm{CuA})$ controls. The lower holotransferrin (plasma iron) and lower expression of transferrin receptor 2 (TfR2), a sensor of plasma iron, correlated well with lower Hamp expression. BMP6 levels were not impacted by $\mathrm{CuD}$ in that study (Jenkitkasemwong et al. 2010). Augmented liver iron can also stimulate Hamp expression (Knutson 2010). In the CuD rat studies mentioned, liver iron levels were higher in $\mathrm{CuD}$ than $\mathrm{CuA}$ rats but this did not correlate with Hamp expression.

Recently, a modification to the commonly used AIN76A and AIN-93G diets has allowed development of $\mathrm{CuD}$ rats without augmentation in liver iron (Bastian et al. 2011). In fact, previous work with AIN-76A diet suggests it contained lower dietary iron, approximately $50 \mathrm{mg} \mathrm{Fe} / \mathrm{kg}$, than needed to support hemoglobin development in pups (Pyatskowit and Prohaska 2008b). Further, the new modified AIN-93G diet, approximately $80 \mathrm{mg} \mathrm{Fe} / \mathrm{kg}$, resulted in augmented liver iron in both $\mathrm{CuA}$ male pups and their dams compared to AIN-76A diet (Bastian et al. 2011).

The purpose of the current studies was to evaluate Hamp expression in $\mathrm{CuD}$ female pups reared on the AIN-76A diet, in $\mathrm{CuD}$ male pups, $\mathrm{CuD}$ dams, and iron-deficient (FeD) dams reared on the new modified AIN-93G diets to elucidate the signaling pathway in $\mathrm{CuD}$ rats that may impact Hamp expression and iron homeostasis.

\section{Materials and methods}

Animal care and diets

In experiment one (Expt. 1), 10 Holtzman sperm-positive rats were purchased commercially (Harlan Sprague-Dawley, Indianapolis, IN) and received either $\mathrm{Cu}$-adequate $(\mathrm{CuA})$ or $\mathrm{Cu}$-deficient $(\mathrm{CuD})$ dietary treatment consisting of a Cu-deficient modified AIN-76A diet (Teklad Laboratories, Madison, WI) containing $0.4 \mathrm{mg} \mathrm{Cu} / \mathrm{kg}$ and
$50 \mathrm{mg} \mathrm{Fe} / \mathrm{kg}$. Normal AIN-76A diet contains approximately $6 \mathrm{mg} \mathrm{Cu} / \mathrm{kg}$. All dams and offspring were fed the $\mathrm{CuD}$ diet. $\mathrm{CuA}$ groups drank water supplemented with cupric sulfate, $20 \mathrm{mg} \mathrm{Cu} / \mathrm{L}$, and $\mathrm{CuD}$ groups drank $\mathrm{Cu}$-free deionized water. Treatment for dams began on embryonic day 7 , and all rats were killed after 5 weeks of treatment.

In Expt. 2, 15 Sprague-Dawley sperm-positive rats were purchased commercially (Charles River, Willmington, MA, USA) and received either $\mathrm{CuA}, \mathrm{CuD}$, or FeD diets modified from the AIN-93G formulation by increasing dietary iron, copper, calcium, and phosphorous to those recommended for reproduction listed in Table 2-2 of the 1995 National Research Council guidelines for rats, described elsewhere (Bastian et al. 2010). All dams were offered deionized water to drink. $\mathrm{CuD}$ diet contained $0.5 \mathrm{mg} \mathrm{Cu} / \mathrm{kg}$ and $78 \mathrm{mg} \mathrm{Fe} / \mathrm{kg}$; FeD diet contained $7.2 \mathrm{mg}$ $\mathrm{Cu} / \mathrm{kg}$ and $5.3 \mathrm{mg} \mathrm{Fe} / \mathrm{kg}$; $\mathrm{CuA}$ diet contained $8.7 \mathrm{mg} \mathrm{Cu} / \mathrm{kg}$ and $80 \mathrm{mg} \mathrm{Fe} / \mathrm{kg}$. Treatment for dams began on embryonic day 2. All dams were killed after 6 weeks of treatment. Nutritional protocols are similar to recent designs (Bastian et al. 2011).

For Expt. 1, one female pup from each litter was sampled on postnatal day 26 (P26), and for Expt. 2, one male pup $\mathrm{P} 25$ from $\mathrm{CuA}$ and $\mathrm{CuD}$ dams was sampled. FeD pups in Expt. 2 did not survive to P25. All rats were maintained at $24{ }^{\circ} \mathrm{C}$ with $55 \%$ relative humidity on a 12-h light cycle (0700-1900 h). All protocols were formally approved by the University of Minnesota Institutional Animal Care and Use Committee.

\section{Tissue collection}

To prevent potential changes induced by anesthetics, pups were decapitated without anesthesia. Upon decapitation, trunk blood was allowed to clot and serum was harvested and stored at $-75{ }^{\circ} \mathrm{C}$ until analysis. An aliquot of blood was used to measure hemoglobin. Liver and spleen were rapidly dissected and a portion used for metal analyses.

Dams were deeply anesthetized with either ketamine/ xylazine (Expt. 1) or carbon dioxide (Expt. 2) prior to cardiac puncture. Plasma was harvested, and an aliquot of liver and spleen was used for metal analyses. Remaining tissue was rapidly frozen and stored at $-75^{\circ} \mathrm{C}$ until analysis.

Biochemical analyses

Diet samples and liver tissues were wet-digested with $\mathrm{HNO}_{3}$ (Trace Metal grade; Fisher Scientific, Pittsburgh, PA, USA), and samples were analyzed for total copper, iron, and zinc content by flame atomic absorption spectroscopy (AAS) (Model AA240 FS, Varian, Walnut Creek, CA, USA) (Pyatskowit and Prohaska 2008a). Plasma or 
serum was analyzed for iron content by AAS following treatment with hot trichloroacetic acid to remove hemoglobin iron as described previously (Pyatskowit and Prohaska 2008a). Hemoglobin was determined spectrophotometrically at $540 \mathrm{~nm}$ after conversion to metcyanhemoglobin (Prohaska 1991). Spleen non-heme iron (NHI) was determined colorimetrically after acid digestion using a modification of an established protocol (Torrance and Bothwell 1968).

\section{PCR methods}

Quantitative real-time PCR was used to evaluate mRNA content of selected hepatic genes following suggested guidelines (Bustin et al. 2009). Total RNA was isolated from liver tissue and quality established spectrophotometrically and by RNA gels (Prohaska and Brokate 1999). The relative mRNA content of hepatic hepcidin (Hamp), ferroportin (Fpn), and bone morphogenic protein 6 (Bmp6) were determined by qPCR using the reference gene glyceraldehyde 3-phosphate dehydrogenase (Gapdh) as described previously (Broderius et al. 2010). Primer pairs for Hamp were $5^{\prime}$ GGC AGA AAG CAA GAC TGA TGA C $3^{\prime}$ (forward) and 5' ACA GGA ATA AAT AAT GGG GCG $3^{\prime}$ (reverse); for Fpn 5' GGT GGT GGC AGG CTC TGT $3^{\prime}$ (forward) and $5^{\prime}$ TTT GAA CCA CCA GGG ACG TC $3^{\prime}$ (reverse); for Bmp6 5' ATG GCA GGA CTG GAT CAT TGC $3^{\prime}$ (forward) 5' CCA TCA CAG TAG TTG GCA GCG 3' (reverse); and for Gapdh $5^{\prime}$ TTC CTA CCC CCA ATG TAT CCG $3^{\prime}$ (forward) and $5^{\prime}$ ACC ACC CTG TTG CTG TAG CCA $3^{\prime}$ (reverse).

Western immunoblot protocols

Pieces of fast frozen liver and spleen were homogenized and used to prepare membranes, and proteins were solubilized as described previously (Mostad and Prohaska 2011). Membrane proteins were mixed with SDS Laemmli sample buffer without boiling for Fpn or boiled for all other proteins and electrophoretically fractionated by SDSPAGE on $10 \%$ gels. Spleen cytosolic samples were treated similarly, but first boiled for $5 \mathrm{~min}$ and fractionated on $15 \%$ gels. Plasma proteins were fractionated on $10 \%$ gels. It was only possible to analyze three plasma samples of each treatment group from Expt. 2 for GDF-15 because a thicker comb and larger plasma volume were required. Separated proteins were transferred to a Protran BA 83 nitrocellulose membrane (Whatman) and treated as described previously to detect the appropriate antigens (Broderius et al. 2010). Membranes were stained with Ponceau $\mathrm{S}$ to ensure equal loading of protein. Immunoreactivity was visualized using SuperSignal chemiluminescence substrate (Thermo Scientific). Chemiluminescence detection and densitometry were carried out using the FluorChem $^{\mathrm{TM}}$ system (Alpha Innotech, San Leandro, CA, USA).

The following antibodies were those used previously or purchased commercially and used at appropriate dilutions: anti-mouse actin (MAB1501, Millipore), mouse anti-human transferrin receptor (TfR1) (13-6800, Zymed Laboratories), goat anti-human ceruloplasmin (C 0911, Sigma-Aldrich), goat anti-mouse GDF-15 (sc-46248, Santa Cruz Biotechnology), goat anti-human transferrin ( $T$ 6265, SigmaAldrich), rabbit anti-scavenger receptor B1 (SRB1) (NB400-104, Novus Biologicals), and rabbit anti-transferrin receptor 2 (TfR2) (sc-48747, Santa Cruz Biotechnology). Affinity-purified rabbit anti-human copper chaperone for superoxide dismutase (CCS) and rabbit anti-rat/mouse ferroportin (Fpn) were characterized previously (Jenkitkasemwong et al. 2010; West and Prohaska 2004).

Statistical analyses

Dietary treatment effects were evaluated by Student's $t$ test after variance equality was tested by $F$ test, $\alpha=0.05$. Dams data in Expt. 2 were analyzed by one-way ANOVA and Tukey's test. Data were analyzed using Microsoft Excel $^{\mathrm{TM}}$ or KaleidaGraph (Synergy Software, Reading, PA, USA). For immunoblot densitometry, a value of 1.0 was assigned to mean pixel density of $\mathrm{CuA}$ samples and then relative individual densities were recalculated. Some other data were normalized for graphic presentation.

\section{Results}

Copper and iron status of rats

Four experimental groups were evaluated after treatment with $\mathrm{CuD}$ or $\mathrm{FeD}$ diets. Female and male $\mathrm{CuD}$ pups had liver copper levels less than $10 \%$ of their $\mathrm{CuA}$ controls (Fig. 1a). CuD dams fed the modified AIN-76A diet had markedly lower liver copper as well (Expt. 1 Dams1). CuD dams fed the modified AIN-93G diet with extra iron, calcium, and phosphorus also had lower liver copper levels than $\mathrm{CuA}$ dams (Expt. 2 Dams2), but liver copper in FeD dams was augmented by $50 \%$ (Fig. 1a).

Liver iron level was not altered by either $\mathrm{CuD}$ diet in rat pups (Fig. 1b). Liver iron was higher in CuD Dams1 than $\mathrm{CuA}$ Dams1; however, liver iron was not augmented in $\mathrm{CuD}$ dams fed the new $\mathrm{CuD}$ diet. As expected, liver iron was greatly lower in $\mathrm{FeD}$ dams averaging $1.88 \mu \mathrm{g} / \mathrm{g}$ for five dams compared $179 \mu \mathrm{g} / \mathrm{g}$ for $\mathrm{CuA}$ dams.

Hemoglobin concentration was lower in all $\mathrm{CuD}$ groups compared to $\mathrm{CuA}$ controls except $\mathrm{CuD}$ Dams2 (Fig. 1c). Mild anemia was observed in FeD dams in this experiment 
Fig. 1 Relative liver copper (a), liver iron (b), hemoglobin (c), and plasma iron concentrations (d) in P26 female pups and Dams1 fed modified AIN-76A diet or P25 male pups and Dams2 fed modified AIN-93G diets. Values are means $\pm \operatorname{SEM}(n=4)$. Cudeficient means (gray fill) were significantly different than $\mathrm{Cu}$ adequate (open fill), $* P<0.05$ (Student's $t$ test). Dams2 data were analyzed by ANOVA. Means with different letters are significantly different, $P<0.05$. Iron-deficient bars (solid fill) are shown
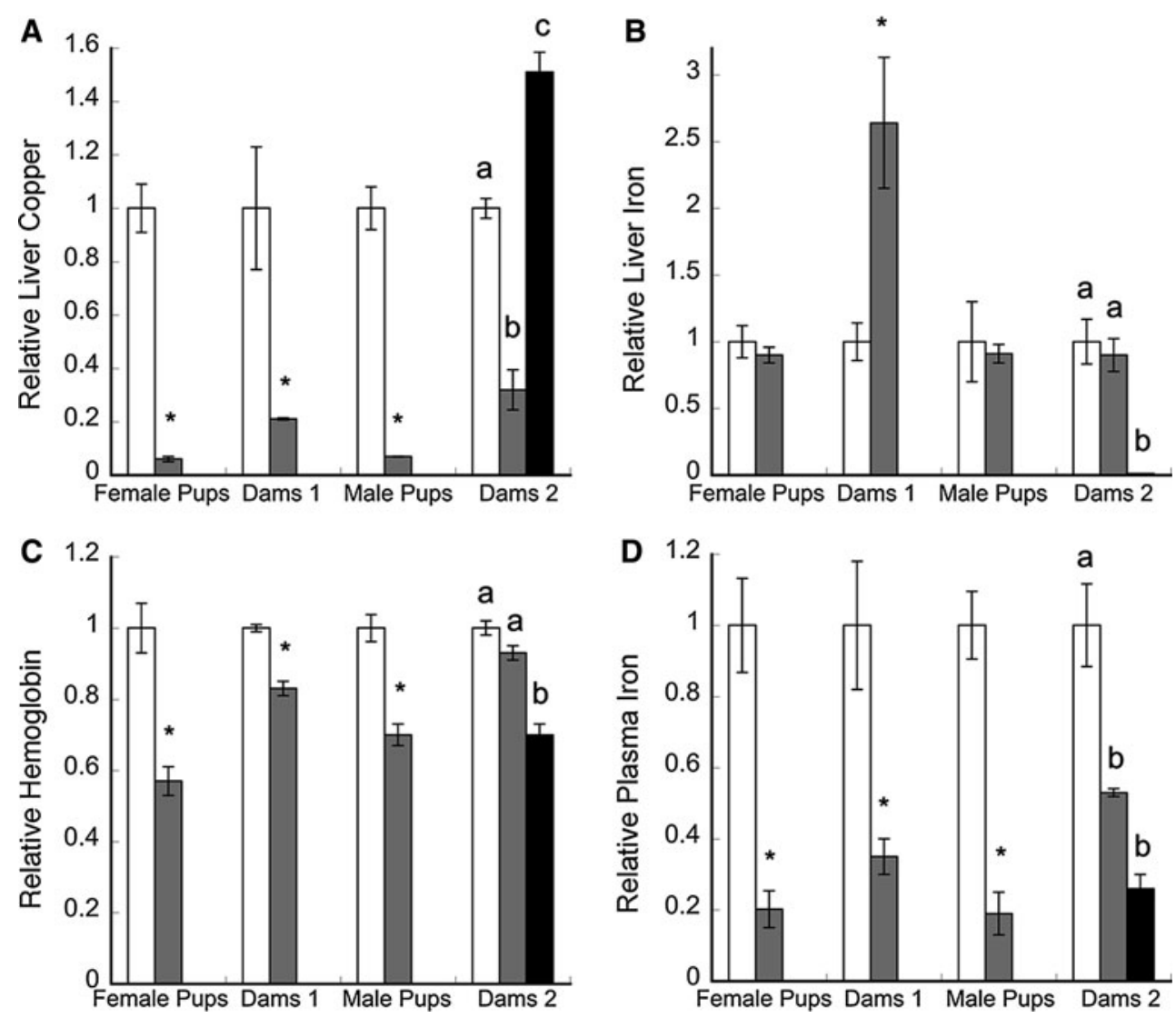

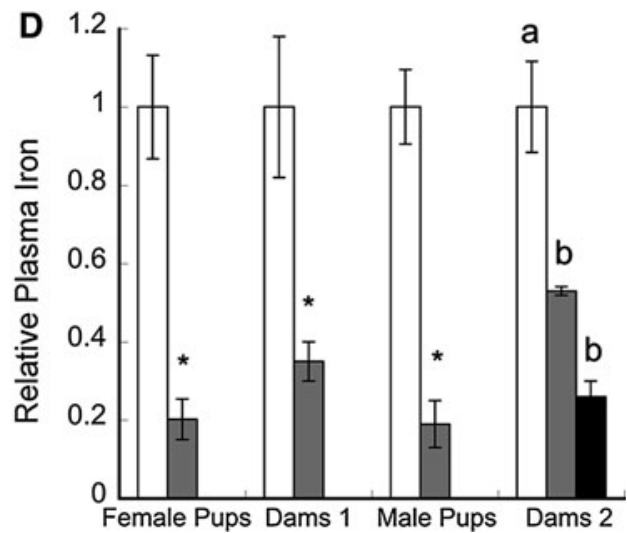

averaging $131 \mathrm{~g} / \mathrm{L}$ compared to $188 \mathrm{~g} / \mathrm{L}$ in the $\mathrm{CuA}$ Dams2. Plasma iron was measured by flame AAS after hemoglobin removal and was found to be lower in all $\mathrm{CuD}$ groups compared to $\mathrm{CuA}$ (Fig. 1d). The relative levels of plasma $\mathrm{Fe}$ in $\mathrm{CuD}$ pups were lower than their respective Dams. Plasma iron level of FeD dams averaged $1.49 \mu \mathrm{g} /$ $\mathrm{mL}$, about $75 \%$ lower than $\mathrm{CuA}$ and $50 \%$ lower than $\mathrm{CuD}$ Dams2 (Fig. 1d). Collectively, these data suggest that $\mathrm{CuD}$ pups and dams displayed signs characteristic of dietary copper deficiency with hypoferremia.

Impact of copper deficiency on selected hepatic gene expression

Liver mRNA abundance of selected genes was evaluated by qPCR using Gapdh as reference gene. The mean quantification cycle $(\mathrm{Cq})$ for Gapdh abundance for a given experiment was equivalent between $\mathrm{CuA}, \mathrm{CuD}$, and $\mathrm{FeD}$ liver samples (data not shown). In agreement with their $\mathrm{CuD}$ brothers studied earlier (Jenkitkasemwong et al. 2010), liver Hamp expression of $\mathrm{CuD}$ female pups was nearly non-detectable compared to $\mathrm{CuA}$ female liver (Fig. 2a). Similar severe suppression of Hamp expression was observed in $\mathrm{CuD}$ male Sprague-Dawley pups that consumed the new $\mathrm{CuD}$ diet with extra iron (Fig. 2b). Neither $\mathrm{CuD}$ female nor male pups had statistically significant alterations in Fpn or Bmp6 mRNA expression (Fig. 2a, b).

In stark contrast to data in pups, the steady state Hamp expression in $\mathrm{CuD}$ dams for both experiments was not impacted (Fig. 2c, d). As a positive control, a 700-fold reduction in Hamp expression in $\mathrm{FeD}$ dams liver was detected (Fig. 2d). Similar to pups, neither Fpn nor Bmp6 mRNA levels were statistically impacted by diet in dams. The unexpected finding of no change in Hamp expression in $\mathrm{CuD}$ dams (Dams1or Dams2) was confirmed several times by re-analysis of fresh cDNA and re-isolation of RNA from an additional sample of frozen liver tissue with equivalent results.

Impact of copper deficiency on selected liver membrane proteins

To evaluate the impact of dietary treatments in pups and dams, liver membranes were prepared, washed free of cytoplasm, and subjected to SDS-PAGE (Fig. 3). Four proteins involved in iron homeostasis and a loading control were evaluated. Densitometry and statistical evaluation of treatment means were conducted (Table 1). The abundance of the loading control SRB1 was quite variable (Fig. 3) despite the appearance of equal loading following Ponceau $\mathrm{S}$ staining (not shown). Thus, another loading control actin 
Fig. 2 Relative hepatic gene expression in P26 female rat pups (a), P25 male rat pups (b) and their respective dams (c) and (d). Values are means $\pm \operatorname{SEM}(n=4)$. Cudeficient means (gray fill) and iron-deficient means (solid fill) were significantly different than $\mathrm{Cu}$-adequate (open bars), $* P<0.05$ (Student's $t$ test or ANOVA)
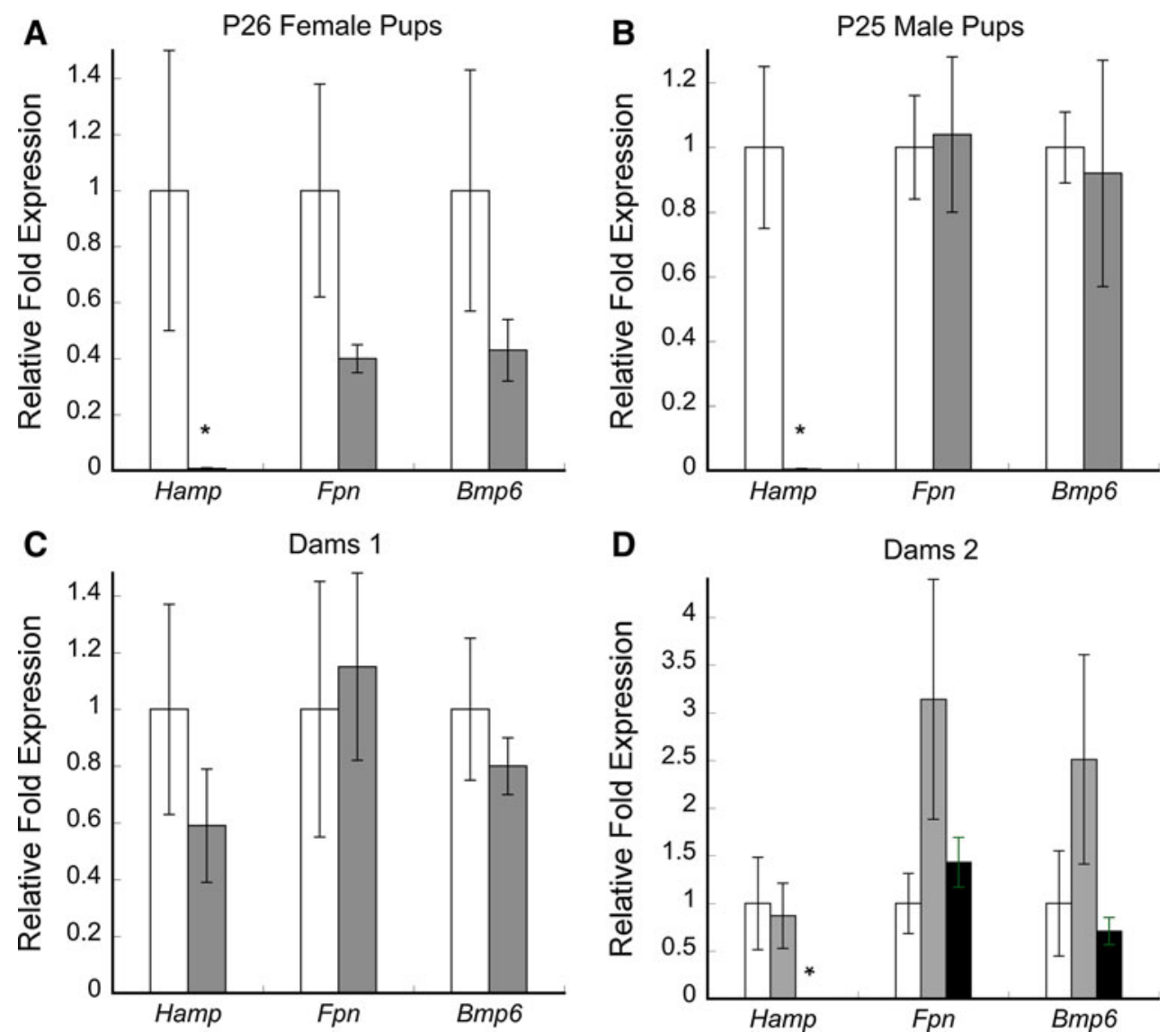

D

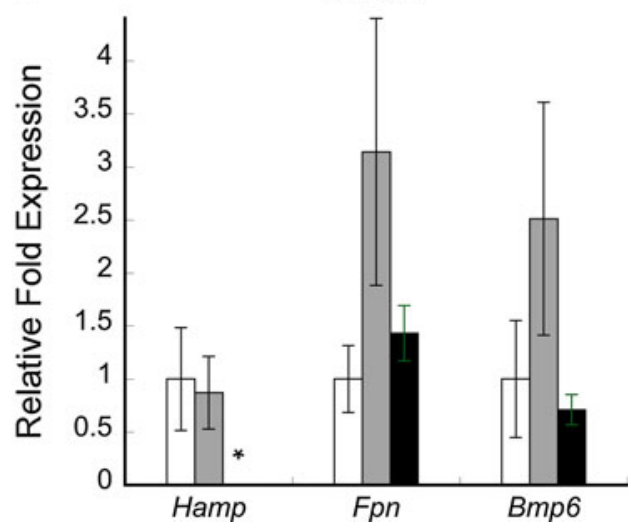

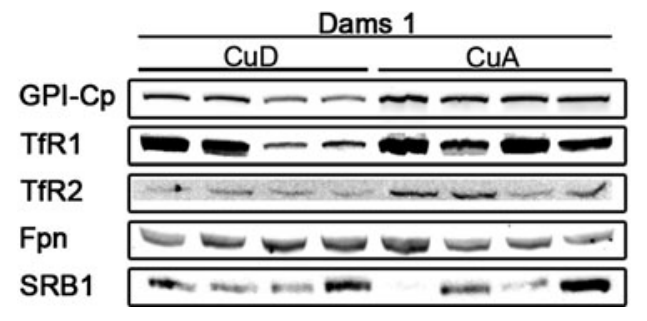

Fig. 3 Hepatic protein levels of GPI-ceruloplasmin, transferrin receptor 1 , transferrin receptor 2 , ferroportin, and scavenger receptor-binding protein 1 following copper deficiency $(\mathrm{CuD})$ or iron

was evaluated. Previously, it was reported that actin was not suitable for liver membranes of rat pups (Mostad and Prohaska 2011). That was confirmed again for the P25 male rats. Relative levels of liver actin for the Dams in Expt 1, like SRB1, were not impacted statistically by dietary treatment. Similarly, Dams in Expt. 2 also did not display differences in actin or SRB1 abundance due to diet.

$\mathrm{CuD}$ Dams fed CuD AIN-76A diet without copper in drinking water (CuD Dams1) had lower abundance of liver GP1-Cp and TfR2 compared to CuA dams. Levels of Fpn and TfR1 were not different between the two groups. Similar results were obtained for $\mathrm{CuD}$ Dams2 fed the new modified AIN-93G diet compared to CuA dams (Fig. 3,
Dams 2

CuA $\mathrm{FeD}$

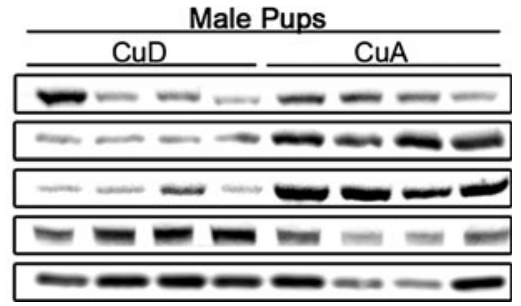

deficiency (FeD) in rat Dams1 fed modified AIN-76A diets, or rat Dams2 and P25 male pups fed modified AIN-93G diets. Immunoblots were performed on $10 \%$ SDS-PAGE gels

Table 1). GP1-Cp and TfR2 abundances were lower, and no significant differences in Fpn or TfR1 were detected. In contrast, the FeD Dams2 had higher liver GP1-Cp and TfR1 expression than $\mathrm{CuA}$ dams, but also lower TfR2 abundance. Liver Fpn was not altered statistically in FeD dams though at first glance density appears lower (Fig. 3, Table 1).

Male pups with lower Hamp expression had a slightly different profile including a robust augmentation in liver Fpn abundance (Fig. 3, Table 1). CuD male pups also expressed lower levels of GP1-Cp, TfR1, and TfR2 compared to $\mathrm{CuA}$ male rats. As a group, all $\mathrm{CuD}$ rats had lower GP1-Cp (reflecting copper status) and lower TfR2 
Table 1 Selected protein expression in liver and spleen, and spleen non-heme iron (NHI) content following dietary copper or iron deficiency in rats

\begin{tabular}{|c|c|c|c|c|c|c|c|}
\hline & \multicolumn{7}{|c|}{ Experimental group } \\
\hline & \multicolumn{2}{|l|}{ Dams1 } & \multicolumn{3}{|l|}{ Dams2 } & \multicolumn{2}{|l|}{ Male pups } \\
\hline & $\mathrm{CuD}$ & $\mathrm{CuA}$ & $\mathrm{CuD}$ & $\mathrm{CuA}$ & $\mathrm{FeD}$ & $\mathrm{CuD}$ & $\mathrm{CuA}$ \\
\hline \multicolumn{8}{|l|}{ Liver levels } \\
\hline GPI-Cp & $0.65 \pm 0.06^{*}$ & $1.00 \pm 0.03$ & $0.64 \pm 0.05^{\mathrm{c}}$ & $1.00 \pm 0.14^{\mathrm{b}}$ & $1.52 \pm 0.10^{\mathrm{a}}$ & $0.40 \pm 0.24 *$ & $1.00 \pm 0.10$ \\
\hline TfR1 & $0.71 \pm 0.22$ & $1.00 \pm 0.14$ & $0.75 \pm 0.13^{\mathrm{b}}$ & $1.00 \pm 0.10^{\mathrm{b}}$ & $4.85 \pm 0.18^{\mathrm{a}}$ & $0.55 \pm 0.02 *$ & $1.00 \pm 0.05$ \\
\hline TfR2 & $0.80 \pm 0.04 *$ & $1.00 \pm 0.09$ & $0.66 \pm 0.09^{\mathrm{b}}$ & $1.00 \pm 0.11^{\mathrm{a}}$ & $0.45 \pm 0.07^{\mathrm{b}}$ & $0.30 \pm 0.05^{*}$ & $1.00 \pm 0.12$ \\
\hline Fpn & $1.06 \pm 0.07$ & $1.00 \pm 0.15$ & $1.14 \pm 0.18^{\mathrm{a}}$ & $1.00 \pm 0.24^{\mathrm{a}}$ & $0.58 \pm 0.05^{\mathrm{a}}$ & $1.74 \pm 0.18^{*}$ & $1.00 \pm 0.12$ \\
\hline \multicolumn{8}{|c|}{ Spleen levels } \\
\hline GPI-Cp & $0.23 \pm 0.01 *$ & $1.00 \pm 0.06$ & $0.12 \pm 0.03^{\mathrm{c}}$ & $1.00 \pm 0.04^{\mathrm{a}}$ & $0.78 \pm 0.07^{\mathrm{b}}$ & $0.51 \pm 0.01 *$ & $1.00 \pm 0.09$ \\
\hline TfR1 & $6.40 \pm 0.71 *$ & $1.00 \pm 0.23$ & $1.44 \pm 0.49^{\mathrm{b}}$ & $1.00 \pm 0.16^{\mathrm{b}}$ & $4.04 \pm 0.22^{\mathrm{a}}$ & $1.94 \pm 0.06^{*}$ & $1.00 \pm 0.09$ \\
\hline Fpn & $0.76 \pm 0.15$ & $1.00 \pm 0.10$ & $0.70 \pm 0.05^{\mathrm{b}}$ & $1.00 \pm 0.13^{\mathrm{b}}$ & $1.54 \pm 0.16^{\mathrm{a}}$ & $1.09 \pm 0.11$ & $1.00 \pm 0.09$ \\
\hline $\mathrm{CCS}$ & $7.35 \pm 0.65^{*}$ & $1.00 \pm 0.32$ & $2.61 \pm 0.14^{\mathrm{a}}$ & $1.00 \pm 0.07^{\mathrm{b}}$ & $1.41 \pm 0.14^{\mathrm{b}}$ & $2.88 \pm 0.37 *$ & $1.00 \pm 0.06$ \\
\hline NHI, $\mu \mathrm{g} / \mathrm{g}$ & $462 \pm 80.7 *$ & $656 \pm 33.5$ & $204 \pm 39.3^{b}$ & $497 \pm 102^{\mathrm{a}}$ & $59.8 \pm 3.89^{\mathrm{b}}$ & $25.0 \pm 4.6^{*}$ & $36.2 \pm 1.1$ \\
\hline
\end{tabular}

Protein expression levels relative to copper-adequate $(\mathrm{CuA})$ rats were determined from densitometric analyses of Western blot data for copperdeficient $(\mathrm{CuD})$ and iron-deficient $(\mathrm{FeD})$ rats (Figs. 3, 4). Means $\pm \mathrm{SEM}(n=4)$ are shown, $* P<0.05$ compared to CuA. Dams 2 data were analyzed by ANOVA, means with differing superscripts are different, $P<0.05$

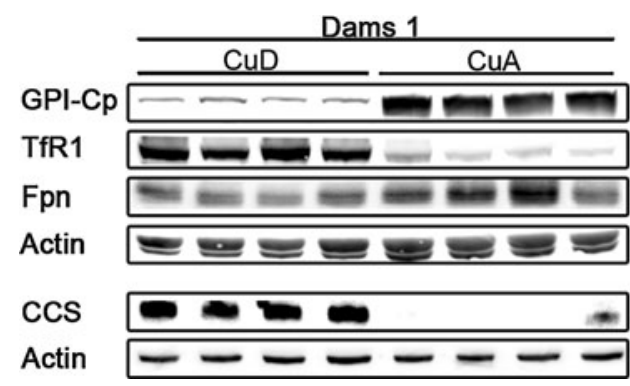

Fig. 4 Splenic protein levels of GPI-ceruloplasmin, transferrin receptor 1 , ferroportin, and actin in membranes or copper chaperone for superoxide dismutase and actin in cytosol following copper deficiency $(\mathrm{CuD})$ or iron deficiency $(\mathrm{FeD})$ in rat Dams1 fed modified

abundance (reflecting iron status). Fpn was only augmented when Hamp was lower (CuD male pups). Interestingly, liver Fpn was not augmented in FeD dams despite low Hamp expression. Membranes from livers and spleens of P26 female rats have been evaluated earlier and were not included (Mostad and Prohaska 2011).

Impact of copper deficiency on selected spleen proteins

CuD Dams1 expressed markedly lower spleen GPI-Cp levels than CuA dams (Fig. 4, Table 1). TfR1 levels were augmented greater than fivefold consistent with lower NHI concentration. Spleen Fpn level was equivalent between $\mathrm{CuD}$ and $\mathrm{CuA}$ dams. Cytosol CCS level was sixfold higher in $\mathrm{CuD}$ than $\mathrm{CuA}$ spleen from Dams1 confirming severe copper deficiency.
AIN-76A diets, or rat Dams2 and P25 male pups fed modified AIN93G diets. Immunoblots were performed on $10 \%$ SDS-PAGE gels for membranes and $15 \%$ gels for cytosol

CuD Dams2 also had a marked reduction in spleen GP1$\mathrm{Cp}$ but no change in Fpn level compared to $\mathrm{CuA}$ dams (Table 1). Interestingly, CuD Dams2 did not have higher TfR1 levels despite lower NHI level (Fig. 4, Table 1). Cytosol CCS was augmented in CuD Dams2 spleen confirming copper deficiency in this organ. Note CCS was not altered in FeD spleen cytosol of Dams2 (Fig. 4, Table 1).

FeD dams expressed a modest reduction in spleen GP1Cp, opposite to the finding in liver (Fig. 4, Table 1). As expected, spleen TFR1 was greatly augmented in FeD dams consistent with low NHI (Table 1). Spleen Fpn of FeD Dams 2 was $50 \%$ higher than CuA levels.

$\mathrm{CuD}$ male pups also displayed a marked reduction in spleen GP1-Cp (Fig. 4, Table 1). TfR1 level was augmented reflecting lower NHI. Spleen Fpn level was not statistically different between $\mathrm{CuD}$ and $\mathrm{CuA}$ rat pups. 
Spleen CCS was augmented in CuD cytosol, as expected, and confirms copper deficiency.

Relationship of plasma iron with liver Hamp

The unexpected failure to detect lower Hamp expression in both groups of $\mathrm{CuD}$ dams prompted further causal analysis. From the evaluation of plasma iron data (Fig. 1), it appeared that $\mathrm{CuD}$ rat pup levels were lower than their mothers. Recall, $\mathrm{CuD}$ pups had very low liver Hamp expression (Fig. 2). Plasma iron level was evaluated versus liver Hamp expression in all rat dams to determine whether absolute plasma iron concentration could explain the difference between $\mathrm{FeD}$ and $\mathrm{CuD}$ dams (Fig. 5). There was clear separation between $8 \mathrm{CuA}$ dams and $8 \mathrm{CuD}$ dams for plasma iron. However, plasma iron level did not correlate with Hamp expression, as many $\mathrm{CuD}$ dams with Hamp expression levels similar to $\mathrm{CuA}$ dams had plasma iron levels as low as some FeD dams with extremely low Hamp expression (Fig. 5).

Selected plasma protein levels following copper and iron deficiency

Plasma from Dams2 fed modified AIN-93G diets were subjected to SDS-PAGE (Fig. 6). Cp levels were greatly diminished in $\mathrm{CuD}$ plasma $(0.47 \pm 0.07)$ compared to $\mathrm{CuA}$ $(1.00 \pm 0.03)$ or $\mathrm{FeD}(0.98 \pm 0.07)$ dams. Transferrin, a loading control, was not altered by either $\mathrm{CuD}$ or $\mathrm{FeD}$ treatment. Levels of GDF-15, a putative erythroid cytokine that suppresses hepcidin expression, were not statistically different among groups and importantly not different between $\mathrm{CuD}$ and $\mathrm{FeD}$ dams with differing hepcidin expression.

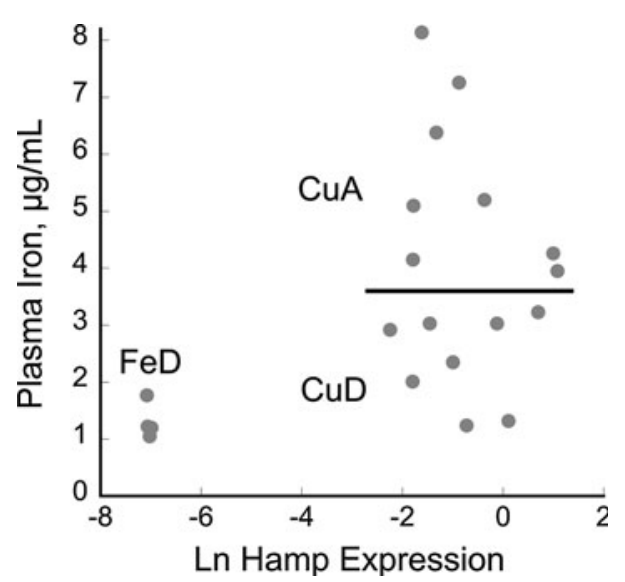

Fig. 5 Correlation between plasma iron concentration and the natural $\log$ of liver Hamp expression in 20 rat dams maintained on either copper-adequate $(\mathrm{CuA})$, copper-deficient $(\mathrm{CuD})$, or iron-deficient (FeD) treatment. A bar separates $8 \mathrm{CuA}$ from $8 \mathrm{CuD}$ values

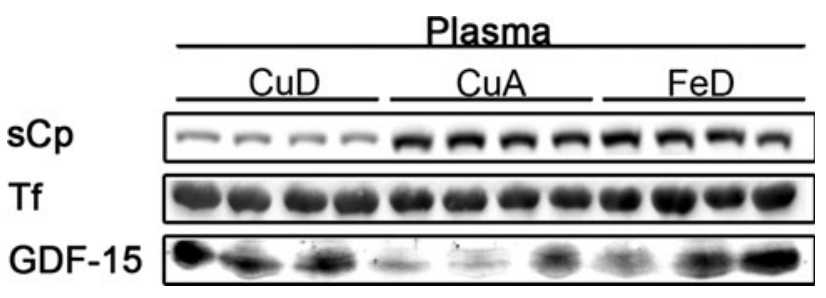

Fig. 6 Plasma protein levels of ceruloplasmin, transferrin, and growth differentiation factor 15 following copper deficiency $(\mathrm{CuD})$ or iron deficiency $(\mathrm{FeD})$ in rat dams fed modified AIN-93G diets. Immunoblots were performed on $10 \%$ SDS-PAGE gels

\section{Discussion}

A salient feature of copper deficiency is the development of anemia first documented experimentally in rats in 1928 (Hart et al. 1928). CuD rats develop hypoferremia as displayed in several rat models in the current studies. Iron deficiency also results in hypoferremia and anemia, and it is commonly suggested that anemia of copper deficiency is caused by a secondary (induced) iron deficiency (Chen et al. 2006; Reeves et al. 2005). However, there are exceptions that question this logic. CuD mice often have no changes in plasma iron but are profoundly anemic (Pyatskowit and Prohaska 2008a). Injection of anemic postweanling $\mathrm{CuD}$ rats and mice with iron does not reverse anemia (Prohaska et al. 1985; Reeves and DeMars 2006; Williams et al. 1983). Further, $C p-/-$ mice and humans with aceruloplasminemia exhibit hypoferremia but only mild anemia, as reviewed elsewhere (Prohaska 2011). However, iron delivery to bone marrow may still be partially responsible for anemia.

Why does hypoferremia develop in $\mathrm{CuD}$ rodents (Pyatskowit and Prohaska 2008c)? One hypothesis suggests limitation in hephaestin, the MCO of enterocytes (Chen et al. 2006; Reeves et al. 2005). Two studies provided evidence of decreased hephaestin abundance and increased intestinal iron following dietary copper deficiency. However, hephaestin mutants (sex-linked anemia (sla)) mice display no anemia as adults nor any reduction in serum iron (Chen et al. 2009). Also, CuD mice with profound anemia do have increased intestinal iron but have normal plasma iron and whole body iron content (Pyatskowit and Prohaska 2008a).

An alternate hypothesis to explain hypoferremia of $\mathrm{CuD}$ is limiting function of $\mathrm{Cp}$ (Osaki et al. 1966). $C p-/-$ mice and people lacking $\mathrm{Cp}$ express severe hypoferremia, as noted above, and also massive hepatic iron overload consistent with the MCO $\mathrm{Cp}$ functioning in iron egress from liver. As reported in current studies with Dams $1, \mathrm{CuD}$ rats also have augmented liver iron. This is true for $\mathrm{CuD}$ mice on both diets used in the current experiments (Mostad and Prohaska 2011; Pyatskowit and Prohaska 2008a). Puzzling 
though is the lack of iron retention in spleen of $\mathrm{CuD}$ rats as shown in the current studies as well as previous work (Mostad and Prohaska 2011; Prohaska and Broderius 2012). CuD rats have extremely low levels of plasma $\mathrm{Cp}$ and low spleen GPI-Cp. Further, puzzling is that iron levels are actually lower in $\mathrm{CuD}$ spleen with low GPI-Cp protein and ferroxidase activity as shown in current data and previously (Mostad and Prohaska 2011). How can iron leave spleen of $\mathrm{CuD}$ rats with low GPI-Cp? Perhaps, spleen macrophages express another MCO such as hephaestin that can compensate for the loss of GPI-Cp. Precedence for this exists in brain of Sla mice in which GPI-Cp is augmented when hephaestin is not functioning (Schulz et al. 2011). This seems unlikely though as $\mathrm{CuD}$ rodents, even if they had splenic hephaestin, should have lower abundance and perhaps non-functional hephaestin based on prior intestinal data (Chen et al. 2006; Reeves et al. 2005).

It is possible that a non-copper-dependent ferroxidase might function. A candidate is APP, the amyloid precursor protein, recently shown to possess ferroxidase activity (Duce et al. 2010). This possibility remains to be tested. It should be noted that spleens of younger $C p-/-$ mice do not display augmented iron, whereas their livers do (Prohaska 2011). Eventually, aged $C p-/-$ mice do demonstrate augmented splenic iron (Harris et al. 1999). Perhaps, APP or some other ferroxidase can explain these splenic iron data. It is also likely that lower splenic iron is the result of lower numbers of circulating erythrocytes following $\mathrm{CuD}$.

A third hypothesis to explain hypoferremia of $\mathrm{CuD}$ rats would involve Fpn. Fpn has been shown by others to be essential for life and for iron egress from enterocytes, liver Kupffer cells and hepatocytes, and splenic macrophages (Donovan et al. 2005). Some argue that membrane Fpn expression depends on membrane $\mathrm{MCO}$ function such as hephaestin and GP1-Cp (De Domenico et al. 2007; Kono et al. 2010). Published data in male rats and data on $\mathrm{CuD}$ rat dams in current experiments demonstrate profound reduction in both liver and spleen GPI-Cp (Mostad and Prohaska 2011). However, current and previously published data suggest that Fpn levels are augmented in $\mathrm{CuD}$ liver and sometimes in spleen (Jenkitkasemwong et al. 2010). Certainly, there is no evidence for lower Fpn following $\mathrm{CuD}$ in rats or mice (Chen et al. 2006; Chung et al. 2004; Jenkitkasemwong et al. 2010; Mostad and Prohaska 2011; Prohaska and Broderius 2012). Hypoferremic Cp $-/-$ mice have augmented intestinal and liver Fpn (Chen et al. 2009). Thus, it seems unlikely that hypoferremia of $\mathrm{CuD}$ is due to limiting Fpn.

Fpn expression is extremely complex and controlled partially by transcriptional, posttranscriptional, and posttranslational mechanisms that involve, at least partially, the well-characterized IRE and IRE-BP system (Knutson
2010). Higher iron levels should result in higher Fpn expression. Thus, augmented Fpn mRNA and protein in liver of $C p-/-$ mice and intestine of $\mathrm{CuD}$ mice follow dogma (Chen et al. 2006, 2009). However, current liver data in CuD rat Dams1, with augmented liver iron, and our previous work in older $\mathrm{CuD}$ rat males and $\mathrm{CuD}$ mice with augmented iron did not detect higher Fpn mRNA.

However, Fpn levels are also dependent on the level of the secreted liver hormone hepcidin (Knutson 2010). In fact, previous work in CuD mice with lower hepcidin and $\mathrm{CuD}$ rats with lower hepcidin both reported higher Fpn protein (Chen et al. 2006; Jenkitkasemwong et al. 2010). This suggests that Fpn level is inversely correlated with hepcidin in $\mathrm{CuD}$ rodents. In fact, in some $\mathrm{CuD}$ mice, liver Fpn was not augmented, likely because hepcidin was not suppressed (Jenkitkasemwong et al. 2010). In the current studies, liver Fpn was augmented in $\mathrm{CuD}$ male rat pups whose hepcidin expression was greatly blunted. Somewhat surprising was the failure to detect augmented liver Fpn in FeD dams that also had greatly suppressed levels of hepcidin. Perhaps, in this case, low hepatic iron may be a factor.

Previous and current data suggest there is a strong correlation between augmented Fpn and decreased hepcidin in $\mathrm{CuD}$ rats (Jenkitkasemwong et al. 2010). What drives lower hepcidin expression in $\mathrm{CuD}$ rats? $\mathrm{In} \mathrm{CuD}$ male and female rat pups, there is a good correlation between low hepcidin and low plasma iron. This was noted previously as $\mathrm{CuD}$ rats with low hepcidin had low plasma iron and $\mathrm{Cu}$ mice with normal hepcidin had normal plasma iron; yet, both $\mathrm{CuD}$ rats and mice were anemic (Jenkitkasemwong et al. 2010). Thus, in this situation, hepcidin is best correlated with holotransferrin rather than anemia. Elegant studies by others with mutant mice suggest transferrin iron is the major determinant of hepcidin expression (Bartnikas et al. 2011; Wilkins et al. 2006).

One signaling pathway involves Tf, TfR1, HFE, and TfR2 (Gao et al. 2009; Schmidt et al. 2008). Previously, it was suggested that TfR2 levels, lower in $\mathrm{CuD}$ rat liver, correlated with lower hepcidin (Jenkitkasemwong et al. 2010). However, data in our current studies detected low TfR2 consistently in all CuD liver samples and in FeD liver; yet, hepcidin was not lower in liver of $\mathrm{CuD}$ dams. Further, hepcidin was not suppressed in $\mathrm{CuD}$ dams that had plasma iron levels equivalent to $\mathrm{FeD}$ dams with major reductions in hepcidin. Thus, it appears there must be some other factor that explains the normal levels of hepcidin in $\mathrm{CuD}$ dams even though they express lower plasma iron and in some cases were anemic.

It is known that bone marrow releases cytokines that may block hepcidin expression (Knutson 2010). The nature of these erythroid regulators remains elusive (Bartnikas et al. 2011). One candidate cytokine, GDF-15, does not appear to be that $\mathrm{CuD}$ factor based on very limited current 
data. Further research will be necessary to evaluate the role of bone marrow in the etiology of anemia following copper deficiency. However, there is evidence for $\mathrm{CuD}$ rodents having abnormal bone marrow metabolism (Collins et al. 2010; Karimbakas et al. 1998). Further research will be necessary to identify factors in the $\mathrm{CuD}$ dams that allow normal hepcidin expression even when hypotransferrinemia is evident. This may involve factors in hepatic signaling or release of erythropoietic factors from bone marrow. Further, it will be important to determine whether iron uptake is limited in $\mathrm{CuD}$ dams due to normal hepcidin expression.

Acknowledgments We appreciate the excellent technical assistance of Krista Hemmesch, Katie Lassi, and Melanie Jokinen. We thank Mitchell Knutson for ferroportin antibody and qPCR primer sequences for Hamp and Fpn. Research was supported by funding from US Public Health Service NIH HD-39708 and the International Copper Association.

\section{References}

Bartnikas TB, Andrews NC, Fleming MD (2011) Transferrin is a major determinant of hepcidin expression in hypotransferrinemic mice. Blood 117:630-637

Bastian TW, Prohaska JR, Georgieff MK, Anderson GW (2010) Perinatal iron and copper deficiencies alter neonatal rat circulating and brain thyroid hormone concentrations. Endocrinology 151:4055-4065

Bastian TW, Lassi KC, Anderson GW, Prohaska JR (2011) Maternal iron supplementation attenuates the impact of perinatal copper deficiency but does not eliminate hypotriiodothyroninemia nor impaired sensorimotor development. J Nutr Biochem 22:1084-1090

Broderius M, Mostad E, Wendroth K, Prohaska JR (2010) Levels of plasma ceruloplasmin protein are markedly lower following dietary copper deficiency in rodents. Comp Biochem Physiol C 151:473-479

Bustin SA, Benes V, Garson JA, Hellemans J, Huggett J, Kubista M, Mueller R, Nolan T, Pfaffl MW, Shipley GL, Vandesompele J, Wittwer CT (2009) The MIQE guidelines: minimum information for publication of quantitative real-time PCR experiments. Clin Chem 55:611-622

Cartwright GE, Gubler CJ, Bush JA, Wintrobe MM (1956) Studies of copper metabolism. XVII. Further observations on the anemia of copper deficiency in swine. Blood 11:143-153

Chen H, Huang G, Su T, Gao H, Attieh ZK, McKie AT, Anderson GJ, Vulpe CD (2006) Decreased hephaestin activity in the intestine of copper-deficient mice causes systemic iron deficiency. J Nutr 136:1236-1241

Chen H, Attieh ZK, Gao H, Huang G, Su T, Ke W, Vulpe CD (2009) Age-related changes in iron homeostasis in mouse ferroxidase mutants. Biometals 22:827-834

Chung J, Prohaska JR, Wessling-Resnick M (2004) Ferroportin-1 is not upregulated in copper-deficient mice. J Nutr 134:517-521

Collins JF, Prohaska JR, Knutson MD (2010) Metabolic crossroads of iron and copper. Nutr Rev 68:133-147

De Domenico I, Ward DM, di Patti MC, Jeong SY, David S, Musci G, Kaplan J (2007) Ferroxidase activity is required for the stability of cell surface ferroportin in cells expressing GPI-ceruloplasmin. EMBO J 26:2823-2831
Donovan A, Lima CA, Pinkus JL, Pinkus GS, Zon LI, Robine S, Andrews NC (2005) The iron exporter ferroportin/Slc40a1 is essential for iron homeostasis. Cell Metab 1:191-200

Duce JA, Tsatsanis A, Cater MA, James SA, Robb E, Wikhe K, Leong SL, Perez K, Johanssen T, Greenough MA, Cho HH, Galatis D, Moir RD, Masters CL, McLean C, Tanzi RE, Cappai R, Barnham KJ, Ciccotosto GD, Rogers JT, Bush AI (2010) Iron-export ferroxidase activity of beta-amyloid precursor protein is inhibited by zinc in Alzheimer's disease. Cell 142:857-867

Fox PL (2003) The copper-iron chronicles: the story of an intimate relationship. Biometals 16:9-40

Gao J, Chen J, Kramer M, Tsukamoto H, Zhang AS, Enns CA (2009) Interaction of the hereditary hemochromatosis protein HFE with transferrin receptor 2 is required for transferrin-induced hepcidin expression. Cell Metab 9:217-227

Harris ZL, Durley AP, Man TK, Gitlin JD (1999) Targeted gene disruption reveals an essential role for ceruloplasmin in cellular iron efflux. Proc Natl Acad Sci USA 96:10812-10817

Hart EB, Steenbock H, Waddell J, Elvehjem CA (1928) Iron in nutrition. VII. Copper as a supplemment to iron for hemoglobin building in the rat. J Biol Chem 77:797-812

Jenkitkasemwong S, Broderius M, Nam H, Prohaska JR, Knutson MD (2010) Anemic copper-deficient rats, but not mice, display low hepcidin expression and high ferroportin levels. J Nutr 140:723-730

Karimbakas J, Langkamp-Henken B, Percival SS (1998) Arrested maturation of granulocytes in copper deficient mice. J Nutr 128: $1855-1860$

Knutson MD (2010) Iron-sensing proteins that regulate hepcidin and enteric iron absorption. Annu Rev Nutr 30:149-171

Kono S, Yoshida K, Tomosugi N, Terada T, Hamaya Y, Kanaoka S, Miyajima H (2010) Biological effects of mutant ceruloplasmin on hepcidin-mediated internalization of ferroportin. Biochim Biophys Acta 1802:968-975

Mostad EJ, Prohaska JR (2011) Glycosylphosphatidylinositol-linked ceruloplasmin is expressed in multiple rodent organs and is lower following dietary copper deficiency. Exp Biol Med 236:298-308

Nemeth E, Tuttle MS, Powelson J, Vaughn MB, Donovan A, Ward DM, Ganz T, Kaplan J (2004) Hepcidin regulates cellular iron efflux by binding to ferroportin and inducing its internalization. Science 306:2090-2093

Osaki S, Johnson DA, Frieden E (1966) The possible significance of the ferrous oxidase activity of ceruloplasmin in normal human serum. J Biol Chem 241:2746-2751

Prohaska JR (1991) Changes in $\mathrm{Cu}, \mathrm{Zn}$-superoxide dismutase, cytochrome c oxidase, glutathione peroxidase and glutathione transferase activities in copper-deficient mice and rats. J Nutr 121:355-363

Prohaska JR (2011) Impact of copper limitation on expression and function of multicopper oxidases (ferroxidases). Adv Nutr 2:129-137

Prohaska JR (2012) Copper. In: Erdman J, Macdonald I, Zeisel S (eds) Present knowledge in nutrition, 10th edn. International Life Sciences Institute, Washington, DC (in press)

Prohaska JR, Broderius M (2012) Copper deficiency has minimal impact on ferroportin expression or function. Biometals 25 (in press)

Prohaska JR, Brokate B (1999) Copper deficiency alters rat dopamine $\beta$-monooxygenase mRNA and activity. J Nutr 129:2147-2153

Prohaska J, Bailey W, Cox D (1985) Failure of iron injection to reverse copper-dependent anemia in mice. In: Mills CF, Bremner I, Chesters JK (eds) Trace elements in man and animals, TEMA 5. Commonwealth Agricultural Bureaux, Farnham Royal, pp 27-32 
Pyatskowit JW, Prohaska JR (2008a) Copper deficient rats and mice both develop anemia but only rats have lower plasma and brain iron levels. Comp Biochem Physiol C 147:316-323

Pyatskowit JW, Prohaska JR (2008b) Iron injection restores brain iron and hemoglobin deficits in perinatal copper-deficient rats. J Nutr 138:1880-1886

Pyatskowit JW, Prohaska JR (2008c) Multiple mechanisms account for lower plasma iron in young copper deficient rats. Biometals 21:343-352

Reeves PG, DeMars LC (2006) Signs of iron deficiency in copperdeficient rats are not affected by iron supplements administered by diet or by injection. J Nutr Biochem 17:635-642

Reeves PG, Demars LC, Johnson WT, Lukaski HC (2005) Dietary copper deficiency reduces iron absorption and duodenal enterocyte hephaestin protein in male and female rats. J Nutr 135:92-98

Schmidt PJ, Toran PT, Giannetti AM, Bjorkman PJ, Andrews NC (2008) The transferrin receptor modulates Hfe-dependent regulation of hepcidin expression. Cell Metab 7:205-214
Schulz K, Vulpe CD, Harris LZ, David S (2011) Iron efflux from oligodendrocytes is differentially regulated in gray and white matter. J Neurosci 31:13301-13311

Torrance JD, Bothwell TH (1968) A simple technique for measuring storage iron concentrations in formalinised liver samples. S Afr J Med Sci 33:9-11

West EC, Prohaska JR (2004) Cu, Zn-superoxide dismutase is lower and copper chaperone CCS is higher in erythrocytes of copperdeficient rats and mice. Exp Biol Med 229:756-764

Wilkins SJ, Frazer DM, Millard KN, McLaren GD, Anderson GJ (2006) Iron metabolism in the hemoglobin-deficit mouse: correlation of diferric transferrin with hepcidin expression. Blood 107:1659-1664

Williams DM, Kennedy FS, Green BG (1983) Hepatic iron accumulation in copper-deficient rats. Br J Nutr 50:653-660 